\title{
Vehicle exterior noise quality evaluation in different elastic rail fastener track sections based on psychoacoustic parameters
}

\author{
L. Li, Q. Zhu \& Y. Xie \\ Institute of Railway and Urban Mass Transit Research, \\ Tongji University, China
}

\begin{abstract}
Vehicle exterior noise has a big effect on residents living alongside rail lines. In order to reduce the influence of metro lines on the environment, elastic rail fasteners have been widely used. However, even though the equivalent sound level A is under the limitation of the national standard; people still complain that the noise affects their lives. In this paper, vehicle exterior noise experiments were performed on two sections which had different types of rail fasteners. The spectrum characteristics were analyzed using different weighted sound level. Furthermore, the characteristics were analyzed by a sound quality objective evaluation based on psychoacoustic parameters. The distribution and influence degree can be preliminarily determined. The results showed that the elastic fastener had an obvious effect on vehicle exterior noise attenuation. Loudness can better evaluate the vehicle exterior noise in different elastic fastener sections, truly reflecting people's subjective sensation as well.
\end{abstract}

Keywords: vehicle exterior noise, noise quality, elastic track, psychoacoustic.

\section{Introduction}

Traffic noise is considered to be one of the most important public annoyances. With the development of transportation, people's daily lives are closely in touch with the metro vehicle and the problem of noise becomes more and more prominent. The vehicle exterior noise greatly affects residents living alongside rail lines [1-4].

In order to reduce the influence of metro lines on the environment, elastic rail fasteners have been widely used. Elastic rail fasteners can effectively isolate the 
vibration to transit from the rail to the substructures. However, even though the equivalent sound level $\mathrm{A}$ is under the limitation of the national standard; people still complain the noise affects their lives.

Traditional acoustic research is mainly on noise reduction. The primary objective is to control the noise intensity. With the development of science and technology, the requirement of noise is no longer staying on the intensity reduction level, has turned to the auditory comfort. The sound quality which people understand will be affected by its own state and the objective environment. Different types of noise have their distinguishing features. The control limitations are also according to different environments. So the noise evaluation is a complex problem combined with noise physics characteristics and the different psychological and physiological people.

\section{Noise evaluation index}

In recent years, there have been a lot of people studying sound quality, and put forward a new concept of modern noise control. Noise control is not only to reduce the sound pressure level, but also to adjust the sound characteristics, to eliminate the disturbing components, to keep pleasant components, which are in accordance with the subjective requirements. At present, in the description of psychological acoustic quality, they are loudness, sharpness, roughness and fluctuation strength which directly related to the subjective feeling of sound.

\subsection{Different weighted sound pressure level}

Sound pressure level is the logarithmic ratio of sound pressure $\mathrm{P}$ to a reference sound pressure $\mathrm{P}_{0}$, and multiplied by 20 . Its unit is $\mathrm{dB}$.

$$
L_{p}=20 \lg \frac{P}{P_{0}}
$$

where the references sound pressure $P_{0}=2 \times 10^{-5} \mathrm{~Pa}$.

According to the characteristic of ISO equal loudness contour, the high, medium and low loudness of the voice were given by different frequency weightings $\mathrm{A}, \mathrm{B}, \mathrm{C}$ and $\mathrm{D}$, to make the measured noise in decibels to have certain correlation with people's subjective loudness perception.

A-weighted sound pressure level is mainly used to simulate the response of the human ear to low intensity noise; sound level $\mathrm{B}$ and $\mathrm{C}$ respectively correspond to response to moderate and high intensity noise. The $\mathrm{D}$-weighted sound pressure level is mainly to simplify the calculation of the perceived noise level. The units of these four kinds weighted sound level are denoted as $\mathrm{dB}(\mathrm{A}), \mathrm{dB}(\mathrm{B}), \mathrm{dB}(\mathrm{C})$ and $\mathrm{dB}(\mathrm{D})$.

International and national standards for the evaluation of all kinds of noise associated with people, most of them were on the basis of A-weighted sound level. But sound level A has great attenuation on low frequency. When the low frequency component of the noise is main, sound level A will underestimate the noise influence. A-weighted sound level cannot explain the effect of the frequency 
selective and complex sound frequency components of the auditory system, nor can explain the nonlinear of the sound intensity. The most sensitive frequency band of the noise to passengers is $1-1000 \mathrm{~Hz}$, so the psychological acoustic parameter is important to evaluate the vehicle exterior noise [5].

\subsection{Loudness}

Loudness is sound intensity felt by human ears; it is a subjective feeling of the sound volume. It mainly depends on the sound pressure (or sound intensity), and is also influenced by the frequency.

There are three loudness calculation models, which respectively proposed by Stevens, Zwicker and Moore. The Stevens model is suitable for the diffusion field, and the Zwicker model is suitable for the free field and the reverberation field. In this paper, we calculated the loudness using the Zwicker model [6, 7].

Loudness is an integral of characteristic loudness at different critical bandwidths on the whole bandwidth. Characteristic loudness and the excitation level of sound critical bandwidth have the following relationship:

$$
\begin{gathered}
N=\int_{0}^{24} N^{\prime} d z \\
N^{\prime}=0.08\left(\frac{E_{T Q}}{E_{0}}\right)^{0.23}\left[\left(0.5+0.5 \frac{E}{E_{T Q}}\right)^{0.23}-1\right]
\end{gathered}
$$

$N$ : loudness;

$N^{\prime}$ : characteristic loudness;

$E_{T Q}$ : excitation corresponding to human ear hearing threshold in free field;

$E_{0}$ : excitation corresponding to the reference sound intensity $I_{0}=10^{-12} \mathrm{~W} / \mathrm{m}^{2}$ );

$E$ : excitation corresponding to calculated sound.

\subsection{Sharpness}

Sharpness is a description of the high frequency sound in the overall loudness weighting. The larger proportion high frequency sound accounted for, the greater the sharpness is. Sharpness also describes the balance of sound in the spectrum. The gravity center of frequency distribution is higher; the sound is sharper. Sharpness has great influence on the comfort degree of sound. Sharpness is higher, the sound is harsher and the sound quality is worse.

The unit of sharpness is acum. The sharpness of $60 \mathrm{~dB}$ narrowband noise, whose center frequency is $1 \mathrm{kHz}$ and the bandwidth is $160 \mathrm{~Hz}$, is 1 acum.

There is no standard method for the calculation of sharpness. In this paper, the calculation formula is as follows:

$$
\mathrm{S}=0.11 \times \frac{\int N^{\prime}(z) \times g(z) \times z \times d z}{\int N^{\prime}(z) \times d z}
$$


$S:$ sharpness;

$N^{\prime}$ : loudness spectrum on a Bark;

$g(z)$ : additive coefficient, which is the function of the critical frequency band.

\subsection{Fluctuation strength and roughness}

Fluctuation strength and roughness are descriptions of the instantaneous changes in the sound signal. The noise signal in the transient changes will lead to two different feelings: low frequency's changes lead to fluctuation; high frequency changes lead to roughness. The roughness is applied to the evaluation of the 20 $200 \mathrm{~Hz}$ modulation frequency of the sound, while the fluctuation strength is used to evaluate the sound of $20 \mathrm{~Hz}$ modulation frequency below.

The unit of fluctuation strength is vacil. The fluctuation strength caused by $60 \mathrm{~dB} 1 \mathrm{kHz}$ pure tone, whose modulation frequency is $4 \mathrm{~Hz}$ and amplitude modulation is $100 \%$, is 1 vacil.

The unit of roughness is asper. The roughness caused by $60 \mathrm{~dB} 1 \mathrm{kHz}$ pure tone, whose modulation frequency is $70 \mathrm{~Hz}$ and amplitude modulation is $100 \%$, is 1 asper.

The calculation method of fluctuation strength and roughness are not standardized. In this paper, the formulas are as follows:

$$
\begin{gathered}
F=C_{f} \times \frac{\int d L(z) \times d z}{\frac{f_{\text {mod }}}{4}+\frac{4}{f_{\text {mod }}}} \\
R=C_{r} \times \int d L(z) \times f_{\text {mod }} \times d z
\end{gathered}
$$

$F$ : fluctuation strength;

$R$ : roughness;

$C_{f}$ : calculation coefficient;

$C_{r}$ : calculation coefficient;

$d L$ : modulation depth, $\mathrm{dB}$;

$f_{\text {mod: }}$ modulation frequency: the modulation frequency is $4 \mathrm{~Hz}$ when the fluctuation strength is calculated; the modulation frequency is $70 \mathrm{~Hz}$ when the roughness is calculated.

\section{Vehicle exterior noise experiment}

The comparison test of the elastic fastener and the general type fastener were conducted in the nonballast track in the Rail Transportation Test Line in Tongji University, when the vehicle speed was $40 \mathrm{~km} / \mathrm{h}$. The test section is straight line. The testing train is Type A for metro, which has one motor car and one trailer. The axial load is $14500 \mathrm{~kg}$.

General fasteners' stiffness is $21-25 \mathrm{kN} / \mathrm{mm}$; elastic fasteners are about $15 \mathrm{kN} / \mathrm{mm}$. Two kinds of fastener were alternatively installed in the same area. 
And the distance between each kind of fastener was $600 \mathrm{~mm}$. When general fasteners were tested, elastic fasteners would be removed and vice versa. Fasteners' installation and alignment were strictly obey the national standard.

Figs 1 and 2 show a testing train and two kinds of fasteners track in the Rail Transportation Test Line. Figs 3 and 4 are the locations and photos of four noise measurement points of the vehicle. The distance between the measuring points and the track axis was $2 \mathrm{~m}, 3.5 \mathrm{~m}, 7.5 \mathrm{~m}$ respectively; and these four points above the top of the rail was respectively $0 \mathrm{~m}, 1.2 \mathrm{~m}, 3.5 \mathrm{~m}$. The test data was collected by the B\&K PULSE vibration noise test system.

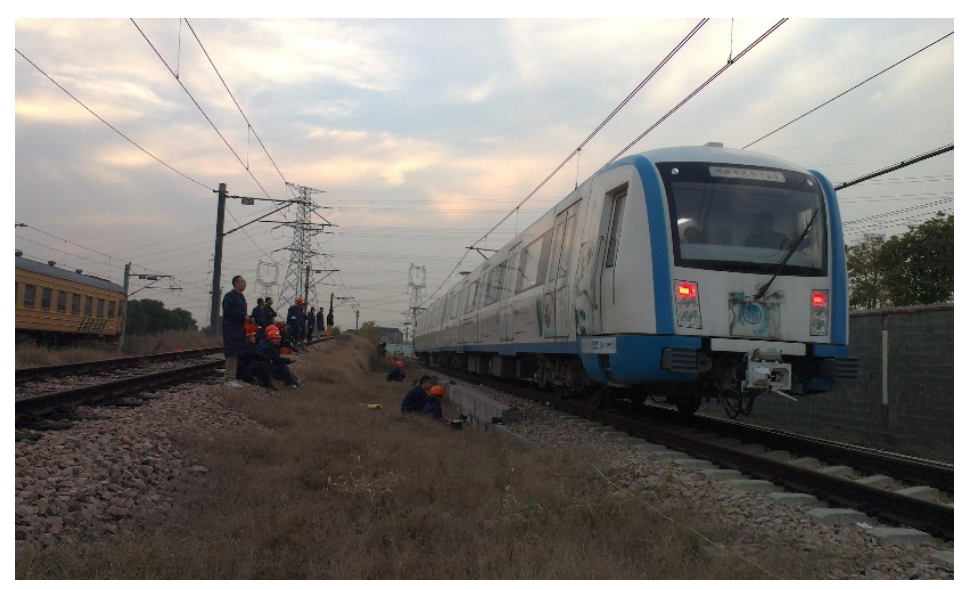

Figure 1: Testing train.

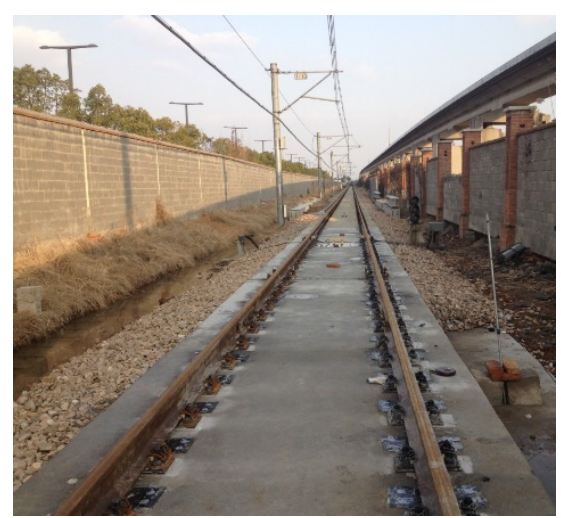

(a)

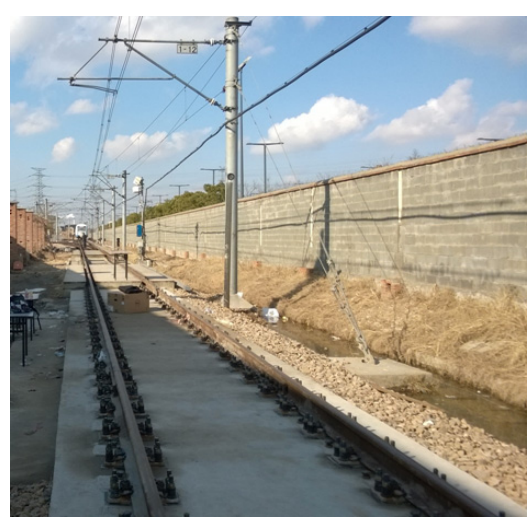

(b)

Figure 2: Common fasteners (a) and elastic fasteners test site (b). 


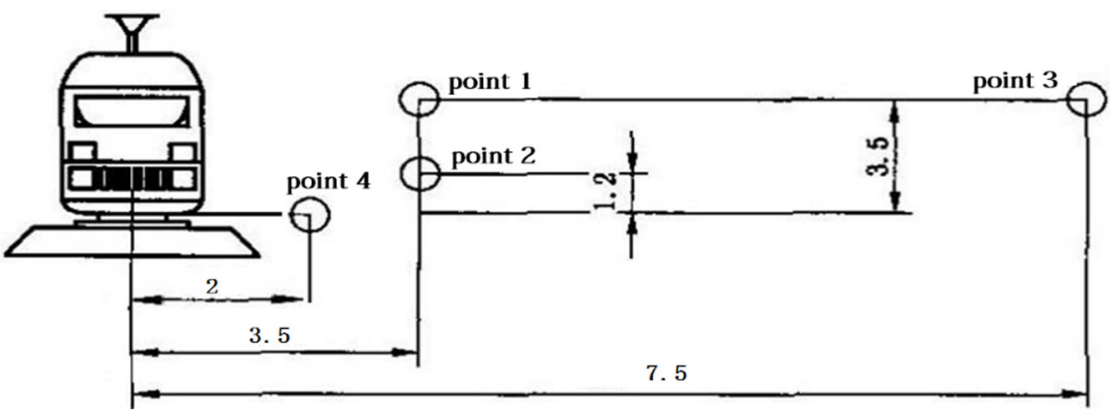

Figure 3: $\quad$ Layout of vehicle exterior noise measuring points (m).
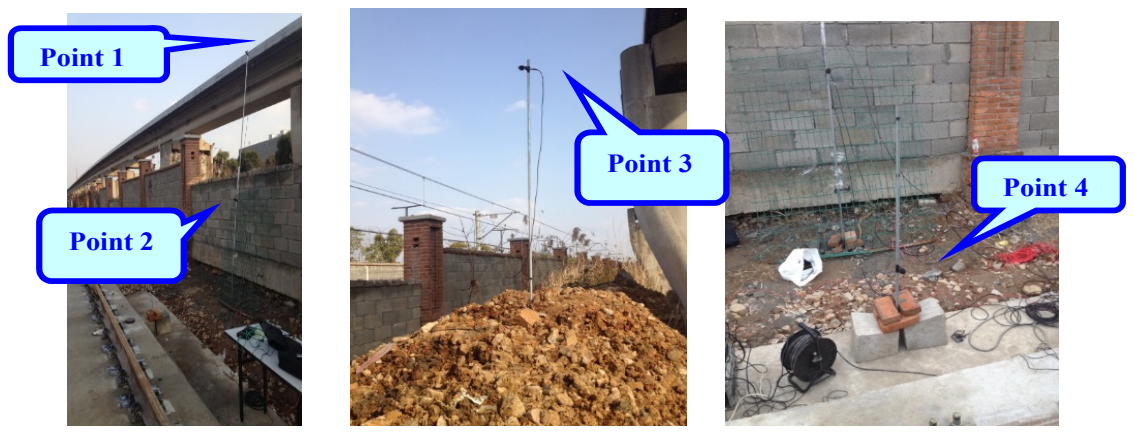

Figure 4: $\quad$ Photos of vehicle exterior noise measuring points.

\section{Vehicle exterior noise analysis}

\subsection{Different weighted sound pressure level analysis}

Linear sound pressure level takes no weight on sound pressure level of each frequency, so it can directly reflect the spectral characteristics. Weighted sound level increase or decrease the sound pressure level of different frequencies by a group of weighted filter, which simulate the human auditory characteristics.

Fig. 5 depicts the spectrum of the vehicle exterior noise measuring Point 1 and Point 3 in the general fastener section. From the figures we can see the effects of different weighted levels. 

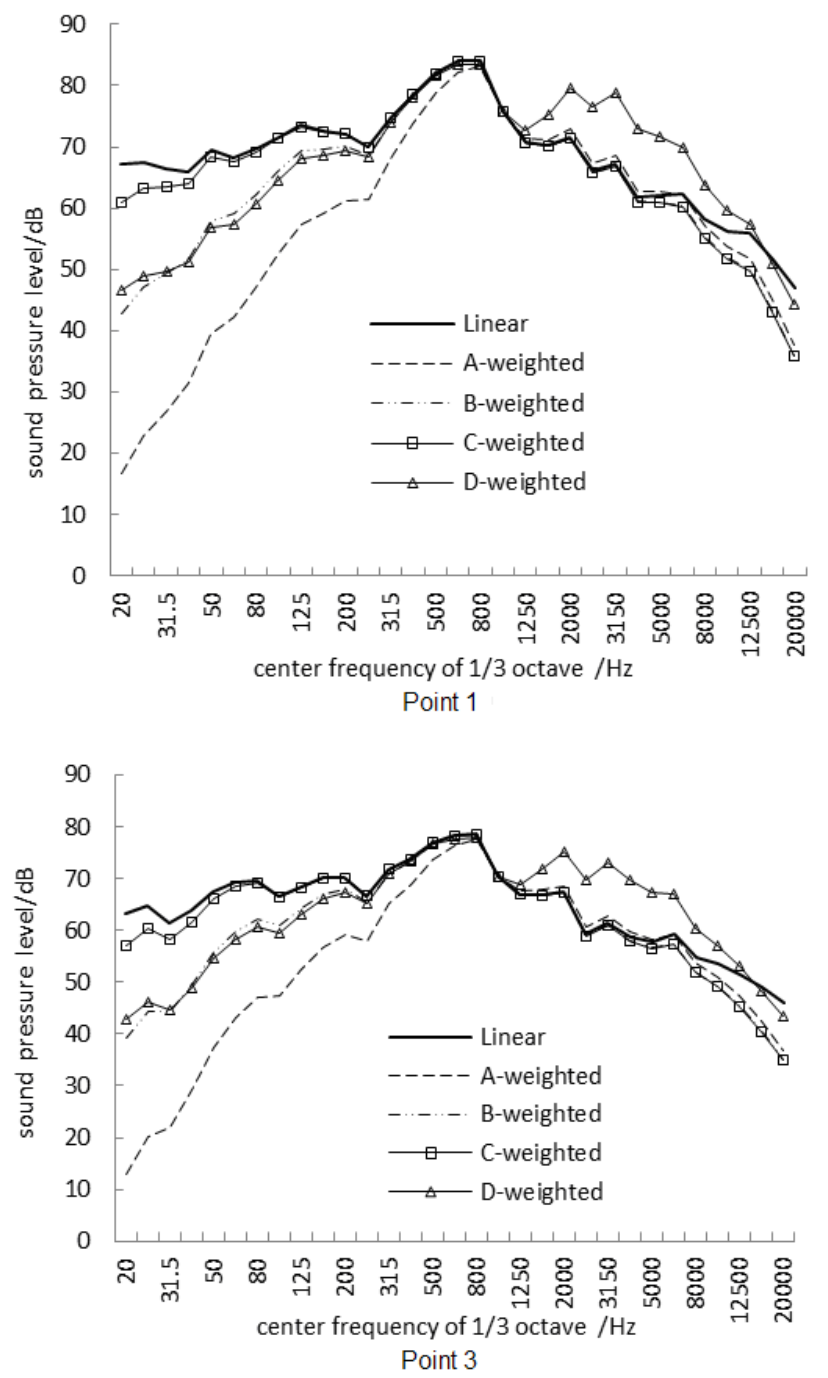

Figure 5: Spectrum of vehicle exterior noise measuring points.

Table 1 shows the different weighted sound levels in two fastener sections with $40 \mathrm{~km} / \mathrm{h}$ running speed.

From Table 1 we know all the sound level of the vehicle exterior noise exceeds the limit value $70 \mathrm{~dB}$ (A) of Environment Quality Standard for Noise (GB 30962008) [8]. Compared with the general fastener section, the sound level of the elastic fastener section is much lower; the difference of the sound level in two fastener sections is about $10 \mathrm{~dB}$, and it even reached $15.25 \mathrm{~dB}$ at Point 4 . 
Table 1: $\quad$ Different weighted sound level of vehicle exterior noise $(d B)$.

\begin{tabular}{|c|c|c|c|c|c|c|}
\hline \multicolumn{2}{|c|}{ Weighting method } & Linear & A & B & C & D \\
\hline \multirow{3}{*}{$\begin{array}{c}\text { General } \\
\text { fastener }\end{array}$} & Point 1 & 90.57 & 87.80 & 89.63 & 90.20 & 90.13 \\
\cline { 2 - 7 } & Point 2 & 95.23 & 92.43 & 94.23 & 94.77 & 94.70 \\
\cline { 2 - 7 } & Point 3 & 85.30 & 82.37 & 84.30 & 85.27 & 85.07 \\
\cline { 2 - 7 } & Point 4 & 97.47 & 94.70 & 96.43 & 97.13 & 97.00 \\
\hline \multirow{3}{*}{$\begin{array}{c}\text { Elastic } \\
\text { fastener }\end{array}$} & Point 1 & 80.20 & 75.45 & 78.03 & 79.60 & 79.63 \\
\cline { 2 - 7 } & Point 2 & 83.90 & 78.48 & 81.13 & 83.20 & 82.63 \\
\cline { 2 - 7 } & Point 3 & 77.63 & 71.80 & 74.58 & 76.68 & 75.88 \\
\cline { 2 - 7 } & Point 4 & 85.15 & 79.45 & 82.25 & 84.48 & 84.05 \\
\hline
\end{tabular}

From the results the elastic fastener has obvious effect on the vehicle exterior noise attenuation.

\subsection{Loudness and sharpness analysis}

According to the characteristics of the human ear loudness perception, comfortable loudness range is within 25 sone (corresponding to $68 \mathrm{~dB}(\mathrm{~A})$ ); when reaching 32 sone (corresponding $74 \mathrm{~dB}(\mathrm{~A})$ ), subjective sensation is noisy and uncomfortable, and it will interfere with our normal work and rest if noise lasts; when it up to 50 sone (corresponding to $80 \mathrm{~dB}(\mathrm{~A})$ ), subjective sensation is very noisy and uncomfortable, and it easily leads to people's irritability; once exceeding 50 sone, it will cause damage to human hearing in this environment for a long time if no protective measures are taken.

Table 2 shows the loudness and sharpness of the vehicle exterior noise in two fastener sections.

From Table 2 we know that almost all the loudness of the vehicle exterior noise in two fastener sections are much higher than 32 sone, and it even reached 96.148 sone at Point 4 in the general fastener section. Compared with the general fastener section, the loudness of the elastic fastener section is much lower; the difference

Table 2: $\quad$ Loudness and sharpness of vehicle exterior noise.

\begin{tabular}{|c|c|c|c|c|c|}
\hline \multicolumn{2}{|c|}{ Different fastener } & Point 1 & Point 2 & Point 3 & Point 4 \\
\hline \multirow{2}{*}{$\begin{array}{l}\text { Loudness } \\
\text { (sone) }\end{array}$} & $\begin{array}{l}\text { General } \\
\text { fastener }\end{array}$ & 63.07 & 83.03 & 46.79 & 96.15 \\
\hline & $\begin{array}{c}\text { Elastic } \\
\text { fastener }\end{array}$ & 44.69 & 59.39 & 34.00 & 67.02 \\
\hline \multirow{2}{*}{$\begin{array}{l}\text { Sharpness } \\
\text { (acum) }\end{array}$} & $\begin{array}{l}\text { General } \\
\text { fastener }\end{array}$ & 1.30 & 1.33 & 1.34 & 1.33 \\
\hline & $\begin{array}{c}\text { Elastic } \\
\text { fastener }\end{array}$ & 1.35 & 1.35 & 1.35 & 1.36 \\
\hline
\end{tabular}


of loudness is about 20-30 sone, and the reduction of vehicle exterior noise in elastic fastener section is about $30 \%$. The sharpness of two fastener sections are almost equal, while the difference is just about 0.01-0.05 acum.

\subsection{Fluctuation strength and roughness analysis}

Table 3 shows the fluctuation strength and roughness of the vehicle exterior noise in two fastener sections.

Table 3: Fluctuation strength and roughness of vehicle exterior noise.

\begin{tabular}{|c|c|c|c|c|c|}
\hline \multicolumn{2}{|c|}{ Different fastener } & Point 1 & Point 2 & Point 3 & Point 4 \\
\hline \multirow{2}{*}{$\begin{array}{c}\text { Fluctuation } \\
\text { strength } \\
\text { (vacil) }\end{array}$} & $\begin{array}{l}\text { General } \\
\text { fastener }\end{array}$ & 0.70 & 0.83 & 0.59 & 0.95 \\
\hline & $\begin{array}{c}\text { Elastic } \\
\text { fastener }\end{array}$ & 0.84 & 1.00 & 0.73 & 1.09 \\
\hline \multirow{2}{*}{$\begin{array}{c}\text { Roughness } \\
\text { (asper) }\end{array}$} & $\begin{array}{l}\text { General } \\
\text { fastener }\end{array}$ & 1.29 & 1.43 & 1.22 & 1.50 \\
\hline & $\begin{array}{c}\text { Elastic } \\
\text { fastener }\end{array}$ & 1.10 & 1.21 & 1.01 & 1.25 \\
\hline
\end{tabular}

It can be known that the fluctuation strength and roughness of two fastener sections are both very close. Compared with the general fastener section, the fluctuation strength of the elastic fastener section is slightly higher; the difference of the vehicle exterior noise is just 0.15 vacil. The change regularity of exterior noise in two fastener sections is not obvious, indicating that the fluctuation strength and roughness are both difficult to reflect the variability of in the human ear sensation when the vehicle exterior noise have changed, although they indeed have little fluctuation.

\section{Conclusion}

In this paper, the vehicle exterior noise in general and elastic fastener sections were test when testing train was running at the speed of $40 \mathrm{~km} / \mathrm{h}$. The data is analyzed by different weighted sound pressure level and sound quality objective evaluation parameters. The results show that:

1) In the general fastener section, the vehicle exterior noise is broadband noise whose spectrum is relatively well-distributed, and it is mainly concentrated in the wide band of $800 \mathrm{~Hz}$.

2) Among sound quality parameters, loudness can better evaluate the vehicle exterior noise in different elastic fastener sections, meanwhile truly reflect human's subjective sensation. The elasticity of the fastener had little effect on sharpness, fluctuation strength and roughness.

3) Compared with the general fastener, although the sound level of the elastic fastener section was slightly higher, the elastic fastener had obvious effect on the vehicle exterior noise attenuation; and the reduction of vehicle exterior noise in elastic fastener section was about $30 \%$. 


\section{Acknowledgement}

The authors would like to acknowledge the support by the National Natural Science Foundation of China (Grant No. 51408434).

\section{References}

[1] Lei X., and Sheng X., The noise and vibration of railway transport, Beijing Science Press, Beijing, 2004.

[2] Mao D., Study on Subjective Evaluation and Analysis Methods on Vehicle Sound Quality, Ph.D. Thesis, Tongji University, 2003.

[3] Fan R., Meng G., Sun X., et al, Interior noise evaluation for high speed traveling train based on psychoacoustial loudness analysis, Journal of Vibration and Shock, 24 (5), 46-50, 2005.

[4] Zhang J., Xiao X., Noise evaluation in the tourist cabin of high-speed train by using aircraft noise criterion, Journal of Mechanical Engineering, 49 (16), 33-38, 2013.

[5] Hellman R., and Zwicker E., Why can a decrease in $d B(A)$ produce an increase in loudness, Journal of the Acoustical Society of America, 82 (5), 1700-1705, 1987.

[6] Zwicker E., and Fasti H., Psychoacoustics: Facts and Models, Second Edited, Springer Verlag, Berlin, 1999.

[7] Moore B., Glasberg B., and Thomas B., A Model for the Prediction of Thresholds, Loudness, and Partial Loudness, Journal of the Audio Engineering Society, 45 (4), 224-239, 1997.

[8] GB 14892-2006, Noise limit and measurement for train of urban rail transit, 2006. 